\title{
Acute Colonic Pseudo-Obstruction After Ventriculoperitoneal Shunt Placement for Normal Pressure Hydrocephalus
}

\author{
Cherry Liu $^{1}$, Daniel Smerin ${ }^{1}$, Isin Comba ${ }^{2}$, Lakhinder Bhatia ${ }^{2}$ \\ 1. Medicine, University of Central Florida College of Medicine, Orlando, USA 2. Internal Medicine, University of Central \\ Florida College of Medicine, Orlando, USA
}

Corresponding author: Cherry Liu, yihrenliu@knights.ucf.edu

\begin{abstract}
Ogilvie's syndrome is a rare postoperative condition commonly referred to as a "colonic pseudo-obstruction" due to the absence of mechanical obstruction. It should be a differential for patients over the age of 60 years who present with nausea, vomiting, and colonic dilatations on imaging. Ogilvie's syndrome following a ventriculoperitoneal (VP) shunt placement is an extremely rare entity with only one other adult patient reported in the English literature. In this case report, we explore the diagnosis and management of a 76year-old patient who presented with abdominal pain and multiple bouts of bilious, non-bloody vomitus two days after a ventriculoperitoneal shunt. The ultimate diagnosis of Ogilvie's syndrome along with imaging and subsequent management is detailed, and diagnosis guidelines and treatment options for Ogilvie's syndrome are analyzed and explained. This case highlights the importance of keeping Ogilvie's syndrome on the list of differentials in a postoperative patient in all abdominal surgeries, even if they are minimally invasive.
\end{abstract}

Categories: Internal Medicine, Gastroenterology, Neurosurgery

Keywords: ventriculoperitoneal shunt, ogilvie's syndrome, colonic pseudo-obstruction

\section{Introduction}

Ogilvie's syndrome is defined as an acute dilatation of the colon in the absence of mechanical obstruction. It is a relatively rare clinical entity with an estimated annual incidence about 100 cases per 100,000 hospital admissions and more common in men over the age of 60 years in the United States [1]. A postoperative state poses significant risk for Ogilvie's syndrome, as $40 \%-50 \%$ of documented cases of acute colonic pseudoobstruction occur after surgery or trauma, most commonly after coronary artery bypass grafting [2]. In this report, we present a 76-year-old man who developed Ogilvie's syndrome on postoperative day 2 after a ventriculoperitoneal (VP) shunt placement. While there can be intra-abdominal complications secondary to VP shunting, more complications are shunt infections followed by cerebral spinal fluid pseudocyst, abscess, and infected fluid [3]. There is only one adult case of Ogilvie's syndrome following VP shunt surgery for

Received 04/03/2020

Review began 04/30/2020 Review ended 05/13/2020 Published 05/26/2020

(c) Copyright 2020

Liu et al. This is an open access article distributed under the terms of the Creative Commons Attribution License CC-BY 4.0., which permits unrestricted use, distribution, and reproduction in any medium, provided the original author and source are credited. normal pressure hydrocephalus in the English literature [4].

\section{Case Presentation}

A 76-year-old man with a past medical history of seizures, NPH, and obstructive sleep apnea was admitted to the hospital for an elective VP shunt for NPH. His past surgeries included laparoscopic cholecystectomy, open appendectomy, and two umbilical hernias including one with a mesh instalment. The surgery went smoothly with no immediate complications and the patient recovered well until on postoperative day 2 ; he developed abdominal distention, constant lower quadrant pain, and multiple bouts of bilious, non-bloody vomitus. His physical exam included vital signs within normal ranges, and was significant for a distended, tympanic abdomen with generalized tenderness, but no rebound or guarding. Initial laboratory tests (complete blood count and complete metabolic panel) were unremarkable. An X ray (Figure $1 \mathrm{~A}$ ) and computed tomographic (CT) scan (Figure 1B) of the abdomen with oral contrast showed severe dilatation of the right and transverse colon with a relative transition section at the splenic flexure. The small bowel was noted to be normal in diameter with no evident obstruction. 


\section{Cureus}

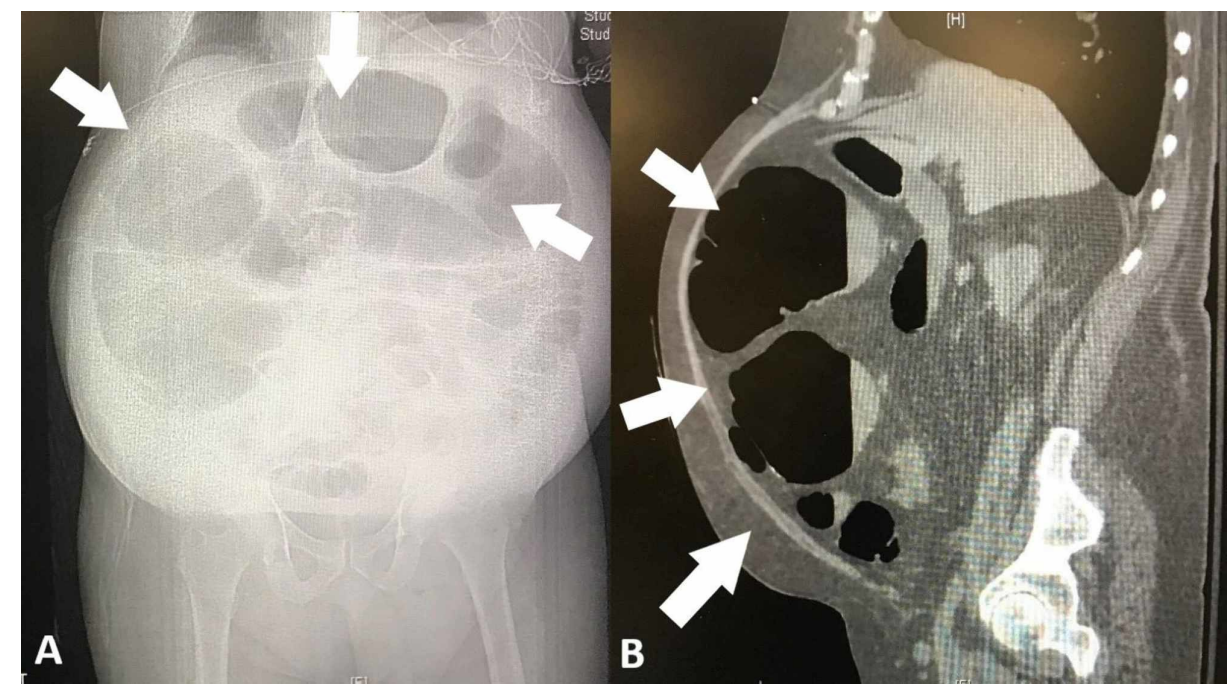

FIGURE 1: Abdominal X-ray revealing moderate to severe dilatation of the colon (A). CT scan with oral contrast showing a severe dilatation of colon (B).

Gas and stool were noted in the rectum. The VP shunt was visualized terminating in the right upper abdominal quadrant around the subhepatic region, and a VP series was not indicated. A nasogastric (NG) tube was placed, and the patient was closely followed with serial abdominal exams and X-rays. On postoperative day 3, he was feeling better in terms of abdominal distension and pain with an NG tube in place, but still failed to have any flatus or bowel movements. Thus, he was started on docusate taken orally, and given a fleet enema. Finally, on postoperative day 5 , the patient had a bowel movement and flatus, which significantly reduced his abdominal pain and resolved his nausea and vomiting. However, on day 8 , his abdominal pain and distension returned. Due to recurrence of the abdominal pain and distension on conservative management, on postoperative day 8 , the patient underwent a decompressive colonoscopy that resulted in the improvement of his abdominal distention, cramping, and pain. A fecal tube was placed following the procedure. However, the symptoms of abdominal distension and pain returned, and he underwent another decompressive colonoscopy, which revealed minimal peristalsis in the examined colonic sections. Abdominal X-rays obtained before (Figure $2 A$ ) and after (Figure $2 B$ ) the second decompressive colonoscopy showed some improvement in colonic distension.

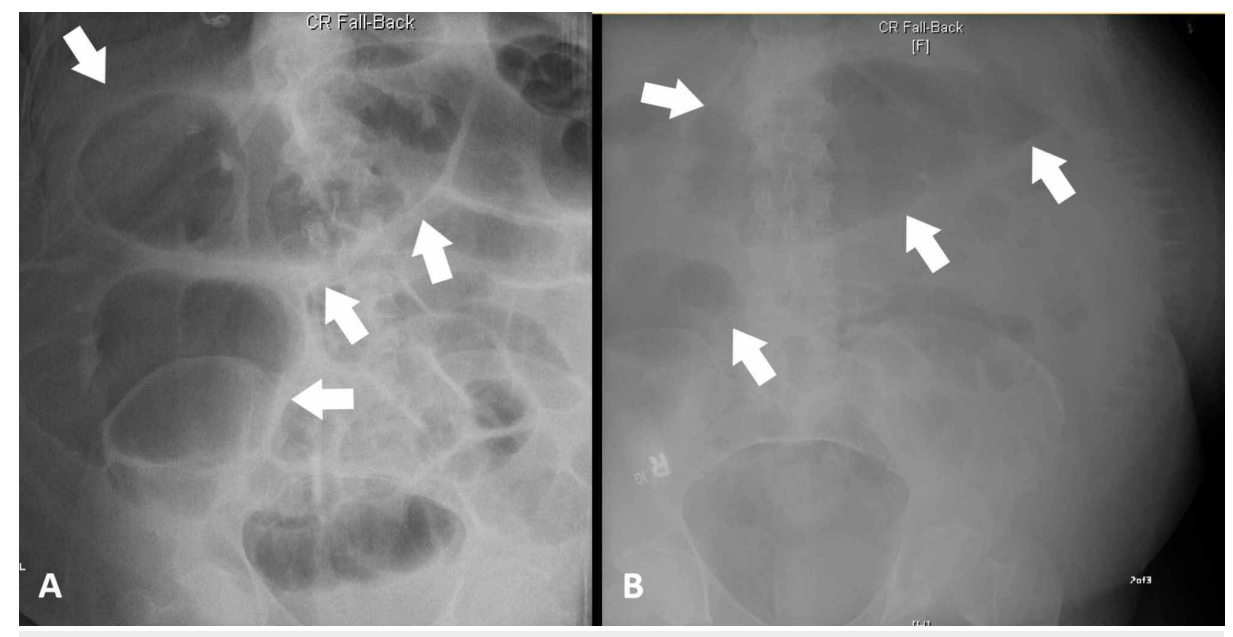

FIGURE 2: (A) Abdominal X-ray in the supine view acquired before the colonoscopy revealing multiple dilated bowel loops that are seen throughout the abdomen. (B) Abdominal X-ray acquired after the decompressive colonoscopy showing some air-filled loops less pronounced than before. 
The patient had a prolonged hospital stay due to persistent recurrent symptoms of nausea, vomiting, abdominal distension, and pain. He responded to the conservative management, did not require another colonoscopy, and was discharged from the hospital after the complete resolution of his symptoms.

\section{Discussion}

In 1948, Ogilvie's syndrome was first described by Sir William Ogilvie, who noted two patients with massive colonic dilations that occurred without mechanical obstruction [1]. This type of colonic dilation is now referred to as a "pseudo-obstruction". At the time, Sir William Ogilvie suspected that this pseudoobstruction was due to neurological derangements that are often seen in malignant disease spreading to the nervous supply [1]. However, more recently the new theory is that there is large-bowel parasympathetic dysfunction. This theory has been supported by the use of parasympathomimetic agents for complete resolution [5]. A postoperative state poses a significant risk factor for Ogilvie's syndrome, as many of the cases in literature review of acute colonic pseudo-obstructions occur after surgery or trauma [6]. While elderly patients with various comorbid conditions are disproportionately affected, Ogilvie's syndrome can be a sequelae of general surgical procedures [7]. Table 1 outlines the results of two large studies including more than 1,000 cases of Ogilvie's syndrome and the known associated conditions of the patients [6,8]. Among the postoperative conditions, neurosurgery ranked at the lowest rate at $1 \%$ and the cause is idiopathic [6].

\begin{tabular}{|c|c|c|c|}
\hline Condition & Example & Number & Percentage \\
\hline $\begin{array}{l}\text { Postoperative } \\
\text { conditions }\end{array}$ & $\begin{array}{l}\text { Coronary bypass, orthopedic surgery (hip especially), urology surgery (including } \\
\text { kidney transplants), thoracic and cardiovascular surgery, neurosurgery }\end{array}$ & 305 & $25.2 \%$ \\
\hline Non-operative trauma & Fractures, burns & 138 & $11.4 \%$ \\
\hline $\begin{array}{l}\text { Pregnancy/gynecologic } \\
\text { issues }\end{array}$ & Cesarean section, gynecological issues, normal pregnancy, vaginal delivery & 76 & $6.3 \%$ \\
\hline $\begin{array}{l}\text { Cardiopulmonary } \\
\text { disorders }\end{array}$ & $\begin{array}{l}\text { Myocardial infarction, congestive heart failure, chronic obstructive pulmonary } \\
\text { disease, acute respiratory failure }\end{array}$ & 208 & $17.2 \%$ \\
\hline Neurologic disorders & Dementia, Parkinson's disease, stroke, Alzheimer's disease, spinal cord injury & 104 & $8.6 \%$ \\
\hline Cancer & Malignant diseases, chemotherapy & 69 & $5.7 \%$ \\
\hline $\begin{array}{l}\text { Intra-abdominal } \\
\text { disorders }\end{array}$ & Hepatic, gastrointestinal, pancreatitis, alcoholism (ascites), cholecystitis & 70 & $5.8 \%$ \\
\hline Systemic disorders & Endocrine and metabolic disease, infection, sepsis, intoxication & 190 & $15.7 \%$ \\
\hline $\begin{array}{l}\text { Retroperitoneal } \\
\text { disorders }\end{array}$ & Acute renal failure, kidney disease & 49 & $4.0 \%$ \\
\hline Idiopathic & Unknown & 58 & $4.7 \%$ \\
\hline
\end{tabular}

TABLE 1: Underlying Conditions in 1,211 Patients From Two Major Studies on Ogilvie's Syndrome

Ogilvie's syndrome is considered a diagnosis of exclusion. Patients commonly present with abdominal distension, discomfort, nausea, and vomiting. Interestingly, some patients will even retain some degree of bowel function resulting in diarrhea due to water hypersecretion. Diagnosis typically requires an abdominal imaging, with CT scan with oral contrast as the gold standard of diagnosis. It is important to utilize the CT imaging to rule out perforation and anatomic or mechanical obstruction. If such imaging is not available, a contrast enema study has been shown to have a sensitivity of $96 \%$ for Ogilvie's syndrome. Most importantly, diagnostic colonoscopy should not be performed due to increased risk of perforation [1].

Treatment for Ogilvie’s syndrome involves conservative, pharmacological, and surgical management. In order to pursue this avenue of treatment, it is important to first rule out mechanical obstruction, ischemia, and perforation [9]. The first-line treatment for Ogilvie's syndrome is conservative management [1]. This consists of observation [6]. In patients with mild uncomplicated Ogilvie's syndrome, initial management includes keeping the patient "nothing by mouth" in addition to the placement of an NG tube to help with decompression [1]. Follow-up imaging should be utilized to determine the efficacy of treatment [1]. Ultimately, this conservative treatment should be used for up to 72 hours; however, if there is no improvement, pharmacologic therapy should be initiated with agents like acetylcholinesterase inhibitors (e.g. neostigmine) that enhance bowel movements [9]. Colonic decompression through colonoscopy is used when conservative and pharmacologic management is insufficient to resolve the pseudo-obstruction [6]. Surgical management is reserved for patients who develop complications such as ischemia or bowel 
perforation [1]. The efficacy of surgery has been reported to be $50 \%$ alone, but up to $88 \%$ if there was concurrent decompression tube placement [2]. Many patients also require multiple decompressions [10].

\section{Conclusions}

Ogilvie's syndrome following a VP shunt placement is an extremely rare complication and can prolong the hospital course. Thus, it is important to have this condition considered as a differential for postoperative patients who experience abdominal pain and discomfort following a VP shunt placement. While most intraabdominal complications following this surgery are infectious in nature, close follow-up of patients experiencing abdominal discomfort along with lack of bowel movement is important, as Ogilvie's syndrome can ultimately lead to serious complications such as ischemia and bowel perforation if unrecognized.

\section{Additional Information \\ Disclosures}

Human subjects: Consent was obtained by all participants in this study. Conflicts of interest: In compliance with the ICMJE uniform disclosure form, all authors declare the following: Payment/services info: All authors have declared that no financial support was received from any organization for the submitted work. Financial relationships: All authors have declared that they have no financial relationships at present or within the previous three years with any organizations that might have an interest in the submitted work. Other relationships: All authors have declared that there are no other relationships or activities that could appear to have influenced the submitted work.

\section{References}

1. Conner S, Mitchell C: Ogilvie Syndrome. StatPearls Publishing, Treasure Island, FL; 2020.

2. Jetmore AB, Timmcke AE, Gathright JB Jr, Hicks TC, Ray JE, Baker JW: Ogilvie's syndrome: colonoscopic decompression and analysis of predisposing factors. Dis Colon Rectum. 1992, 35:1135-1142. 10.1007/bf02251964

3. Chung JJ, Yu JS, Kim JH, Nam SJ, Kim MJ: Intraabdominal complications secondary to ventriculoperitoneal shunts: CT findings and review of the literature. Am J Roentgenol. 2009, 193:1311-1317. 10.2214/ajr.09.2463

4. Katzir M, Abeshaus S, Attia M, Zaaroor M: Ogilvie's syndrome following ventriculoperitoneal shunt surgery for normal pressure hydrocephalus. Acta Neurochir. 2014, 156:787-788. 10.1007/s00701-014-2014-Z

5. Chudzinski AP, Thompson EV, Ayscue JM: Acute colonic pseudoobstruction . Clin Colon Rectal Surg. 2015, 28:112-117. 10.1055/s-0035-1549100

6. Vanek VW, Al-Salti M: Acute pseudo-obstruction of the colon (Ogilvie's syndrome). An analysis of 400 cases. Dis Colon Rectum. 1986, 29:203-210. 10.1007/bf02555027

7. Wells CI, O'Grady G, Bissett IP: Acute colonic pseudo-obstruction: A systematic review of aetiology and mechanisms. World J Gastroenterol. 2017, 23:5634-5644. 10.3748/wjg.v23.i30.5634

8. Wegener M, Borsch G: Acute colonic pseudo-obstruction (Ogilvie's syndrome). Presentation of 14 of our own cases and analysis of 1027 cases reported in the literature. Surg Endosc. 1987, 1:169-174. 10.1007/bf00590926

9. Vantrappen G: Acute colonic pseudo-obstruction . Lancet. 1993, 341:152-153. 10.1016/0140-6736(93)90010e

10. Geller A, Petersen BT, Gostout CJ: Endoscopic decompression for acute colonic pseudo-obstruction . Gastrointest Endosc. 1996, 44:144-150. 10.1016/s0016-5107(96)70131-1 